\title{
Research on Industrial innovation and development Based on Location Advantage Theory
}

\author{
Qi Zhang ${ }^{1,2, a}$, Jinjiang $\mathrm{He}^{1, \mathrm{~b}^{*}}$ and Ning Cai ${ }^{1, \mathrm{c}}$ \\ ${ }^{1}$ School of Public Administration, Zhejiang University, Hangzhou 310058, China \\ ${ }^{2}$ Lishui University, Lishui, 323000, China

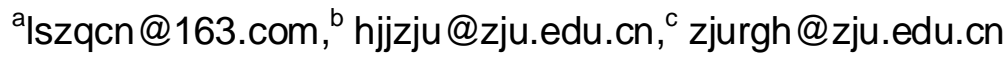

Keywords: Location advantage theory; Industry transfer; Location advantage

\begin{abstract}
This paper discusses the location advantages of different industrial agglomeration areas during the industrial transfer. this paper analyzes the use of location advantage theory in the process of industrial transfer. Discussing the source of location advantage is expounded from the aspects of government guidance and market competition, find out that the location advantage change is a dynamic process and be influenced by environment. Based on this, this paper discusses the problem of location selection in the process of industrial transfer and gives the reasonable path in the process of industrial transfer.
\end{abstract}

\section{A Review of Location Advantage theory}

Location advantage refers to a region of an objective existence that can be conducive to industrial development and layout of the regional favorable factors. David Ricardo proposed the Theory of Comparative Advantage, and comparative advantage theory suggests that trade is derived from the relative difference, not the absolute difference. John Dunning's international production eclectic theory summed up the three most essential elements in determining international and international direct investment: ownership advantages, location advantages and market internalization advantages. Location advantage mainly refers to the advantages of the environment. In this theory, it is pointed out that the main conditions: labor costs, market potential, trade barriers and government policies. Location advantage is a comprehensive concept because individual advantages are often difficult to be a regional advantage. Location advantage includes factor endowments advantages and government policy advantages and many other aspects.

\section{Industrial Transfer Path of Yuyao City}

Yuyao City is an economically developed, competitive city in Zhejiang Province. Yuyao City has a solid industrial base, mainly concentrated in household appliances, machinery and other traditional industries. Traditional resource consumption, unsustainable production model gradually eliminated, which is the demand in the background of industrial transformation. In recent years, the government of Yuyao makes coordinated development pattern through the agglomeration development, intensive development, innovation and development and recycling.

Human Environment. Human environment includes political, social, cultural, population, technology and other external environment. In the political environment, as a city in ECONOMIC TOP100 of China, the Government attaches great importance to industrial upgrading and transformation. In culture, Yuyao City is located in eastern China, with a high sense of innovation and entrepreneurship. In the population, with the development of economic level and the disappearance of the demographic dividend, the labor cost is gradually rising, some enterprises lack of employment. Some low-profit enterprises due to the treatment of employees and other enterprises have gaps, leading to the loss of old employees.

Natural Environment. Natural resources refer to the immobility of natural resources, including land, water and other factors of production. Enterprise development is still very significant constraints on land resources. Nowadays land resources are generally scarce, and not meet 
industrial land demand. Land prices soaring, some areas facing the plight of land not be levied on the continuous reduction of enterprises, enterprises in the local there is no living environment, was forced to migrate to the field. With the constraints of the natural environment, enterprises can only change the status quo through space transfer.

Geographical Environment. Geographical environment mainly refers to traffic, regional environment and so on. Yuyao City is located in the coastal economic zone, land transport network is very developed, so shipping conditions are ripe. In regional environment, the development of marine economy has risen into national strategy, industrialization and urbanization development space have effectively expanded, and the effect of "bridge economy" has gradually emerged.

\section{Analysis of Industrial Transfer Path in Yuyao City}

First, Natural Environment and Geographical Constraints. Through capacity adjustment and revitalize the stock to improve the level of industrial land, and effectively ease the tension of land use, so it can promote industrial economic development. At the same time, through the introduction of talent for industrial transformation and upgrading to provide technical support, use technology to promote regional development, to bring new vitality for the old urban industrial park, improve production efficiency and achieve optimal allocation of resources.

Second, Human Environment in the Economic and Technological Constraints. Using of geographical advantages based on high-tech industrialization, and extended to both ends. New industrial sector focuses on the development of equipment manufacturing, electronic information, new energy, new materials and other industries, the introduction of industrial projects to be new economic growth point. According to this, build a strategic emerging industry cluster, the characteristics of industrial belt and urban industrial agglomeration area

Third, Natural Environment and Geographical Elements of the Constraints. Expand new regional development and make full use of the new region of the natural environment and geographical advantages. For example, the Binhai New City is the most important block in Yuyao industrial economic development. Binhai New City has sea and land traffic advantages. The government provides a good environment for Binhai New City by policy support. The new city infrastructure gradually improved for large enterprises, large projects to create a good landing conditions.

\section{The Mechanism Analysis of Regional Advantages Formation}

According to the path of Yuyao's industrial transfer, we summarize the reasons. Under the assumption that the natural resource endowment is relatively balanced, there are two main sources of location advantages.

First, the Government Guide. Government has a leading role in planning guidance, public services, policy support and environmental construction and other aspects. The government changes the external environment in a region through administrative intervention. Through the planning and guidance, it provides production facilities for enterprises to create regional characteristics of industry and achieve industrial agglomeration. Through the improvement of public services we speed up infrastructure construction, to provide enterprises with good production services to reduce business costs, to attract enterprises to settle down by creating a good environment, enhance regional innovation capacity.

Second, the Market Regulation. The market should be a basic role in the allocation of resources and then it can enhance the enterprise as a market competition for the overall competitiveness of the main. The market adjusts the allocation of resources, so that the elements in the market free pricing. Through continuous dynamic changes and regulation we can achieve industrial transfer. At the same time, homogeneous enterprises in the same region are seeking more benefits and will try to find a new production factor lower cost of the appropriate area, so as to promote industrial transfer. Large enterprises in order to expand the new production and market areas, will achieve the initial exploration of industrial transfer. 
Third, the Government Guidance and Market Regulation of Both. In most cases, we need to combine the two to speed up industrial transfer, promote industrial restructuring and upgrading. The theoretical logic behind the two means is to change the environment, reduce production costs or enhance corporate profits, thereby attracting enterprises to new location selection, to achieve industrial transfer, the emergence of new industrial agglomeration.

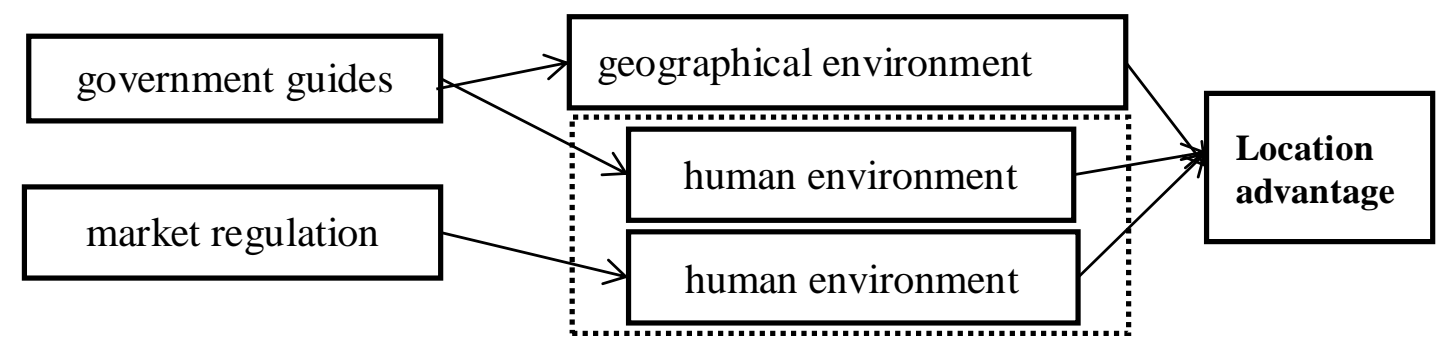

Figure 1. Construction of location advantage path

\section{Summary}

Through the analysis of Yuyao's industrial transfer case analysis and the analysis of the location advantage mechanism, we get several following revelation.

The Reason of Industry Transfer is the Change of Location Advantage. We analyze the path of industrial transfer from the perspective of location advantage theory. From this path, we can see that the reason for the occurrence of industrial transfer is the change of location advantage. When the advantage of the new location is enough to attract the enterprise, the enterprise will be transferred and the industrial transfer will take place.

Dynamic Changes in Location Advantages. Location advantage is a dynamic change process that will change over time. From Yuyao's industrial transfer path, we can find that the path is based on the location advantage, location advantage is not static, can be built out. The dynamic changes of location advantages can be adjusted by the government and the market.

New Location Selection: Combined with Three Paths. Respectively, from the government guidance and market regulation, change the environmental elements can be changed to build a new location advantage. The new location selection should be based on the field situation.

\section{Acknowledgements}

This research was supported by Zhejiang Provincial Natural Science Foundation of China: Study on the generating mechanism of corporate strategic entrepreneurship: viewing from a perspective of network reconfiguration. NO. Y17G020006.

\section{References}

[1] Dunning, John H. International Production and the Muhinational Enterprise, George A11eu \& Unwin, London 1981,102-110;

[2] Pau1. R. Krugman, Increasing Returns and Economic Geography[J], Journal of Political Economic 1991, 99(3);

[3] He C. Theory of Location Advantage of Minnan Folk Customs in Cross-strait Cxchanges[J]. Fujian-Taiwan Cultural Research, 2013.

[4] Xiong Z, Shen C. Tibet Agricultural and Animal Husbandry Structural Adjustment Based on Comparative Advantage Theory[J]. Journal of Shaanxi Vocational \& Technical College, 2008.

[5] Wang L P. Comparative Advantage Theory and Its Revelation to China's Foreign Trade[C]// International Conference on Management and Service Science. IEEE, 2009:1-4.

[6] Johnson B J T. Location and trade theory : industrial location, comparative advantage, and the geographic pattern of production in the United States[J]. 
[7] Olulade O A, Jamal N I, Koo D S, et al. Neuroanatomical Evidence in Support of the Bilingual Advantage Theory.[J]. Cerebral Cortex, 2016, 26(7):3196.

[8] Schneider G E. Sweden's Economic Recovery and the Theory of Comparative Institutional Advantage[J]. Journal of Economic Issues, 2007, 41(2):417-426.

[9] Costinot A, Donaldson D. Ricardo's Theory of Comparative Advantage: Old Idea, New Evidence[J]. American Economic Review, 2012, 102(3):453-458.

[10] Shi Z F. Review and Expectation of the Economic Communication between Fujian and Taiwan-Based on the Location Advantage Variance Theory[J]. Taiwan Research Quarterly, 2008. 